\title{
INSTITUCIONES, INVESTIGADORES Y COMUNIDADES INDÍGENAS CHAQUEÑAS. TRIANGULACIÓN DE INTERESES EN TORNO AFONDOS FOTOGRÁFICOS ESTATALES
}

\author{
Institutions, researchers and Chaquean indigenous communities \\ Triangulation of interests around State photographic archives
}

Mariana Giordano

\section{Resumen}

La constitución de fondos documentales fotográficos que surgieron de intereses estatales desde fines del siglo XIX se presenta como una de las tantas modalidades de perpetuación de la captura de los "otros" indígenas, que responde a su vez a las maneras de definir la ciencia, de afirmar el poder del Estado sobre los "otros" y de constituir identidades nacionales y memorias recortadas.

Este artículo se introduce en el mundo de los fondos fotográficos de indígenas del Gran Chaco teniendo en cuenta que los mismos no son construcciones de existencia neutra e invariable, sino que tienen una "vida" que refleja los intereses de diversos agentes que lo guardan y/o que pretenden utilizarlos, difundirlos o poseerlos. A la vez, indaga en el rol que las fotografías desempeñan en la construcción de memorias en las comunidades indígenas chaqueñas actuales y la legitimidad que éstas poseen en las demandas por las mismas, poniéndose en discusión la cuestión de la "propiedad" de las imágenes. Tales reflexiones se consideran en torno a los conceptos de hegemonía y colonialidad del poder.

De tal forma, planteamos una mirada triangular hacia las instituciones -en particular las estatalesque conservan las imágenes, hacia nuestro propio interés y rol de investigador sobre las fotos en estudio y hacia las intenciones y demandas de las comunidades indígenas chaqueñas actuales respecto de estos fondos.

$<$ Archivos fotográficos $><$ hegemonía $><$ colonialidad del poder $><$ indígenas $><$ Gran Chaco $>$

\begin{abstract}
The constitution of documentary photography from states' interests comes from the late nineteenth century and it is presented as one of the many modalities of perpetuating the capture of the "other" indigenous. That situation responds to the different ways of defining science, to assert state power over "others" and to establish national identities and biased memories.

This article introduces into the world of photographic collections of indigenous of the Gran Chaco taking into account that they are not neutral constructions of unchanging existence; eventhough, they have a "life" that reflects the interests of different stakeholders who keep them or intend to use, spread
\end{abstract}


Giordano. Instituciones, investigadores y comunidades indígenas chaqueñas.

or possess them. Besides, we analyze the role that these photographs have in building memories within Chaco indigenous communities today. Therefore, we also call into question the copyright or "property" of images. These reflections are considered around the concepts of hegemony and coloniality of power.

Thus, there is a triangular look towards the institutions, -including state ones- that preserved the images, to our own interest and our role as researchers on photos and into the intentions and demands of Chaco indigenous communities.

$<$ Photo archives $><$ hegemony $><$ coloniality of power $><$ indigenous $><$ Gran Chaco $>$

\section{Introducción}

Las capturas del indígena en la Argentina -como en otros países latinoamericanos- se han dado de diferentes formas y siguiendo diversas estrategias: una de ellas ha sido la "captura" en imágenes fotográficas, que en función de los intereses de los emisores o comitentes de las mismas, fueron conservadas en archivos públicos o colecciones privadas, convirtiéndose éstos en repositorios que mantienen formas de capturas contemporáneas, que deben entenderse desde el concepto de hegemonía como también el de colonialidad del poder. Desde los aportes de Williams, se entienden los procesos hegemónicos -atendiendo a la contra hegemonía como también las hegemonías alternativas- como la interrelación de valores, significados y prácticas fundamentales en la producción cultural. Es la tradición la que lleva a que seleccionar y sintetizar los significados y las prácticas que las instituciones incorporan, constituyéndose en los pilares de lo hegemónico (Williams, 2000). Se entiende que estos procesos hegemónicos no son homogéneos y compactos, sino que presentan pliegues y son cambiantes, al decir de Williams "Una hegemonía dada es siempre un proceso... Es un complejo efectivo de experiencias, relaciones y actividades que tiene límites y presiones específicas y cambiantes..." (Williams, 2000:134). En este contexto, se entiende que "la cultura es uno de los lugares centrales en la lucha por la hegemonía" (Walsh en Richard, 2010:97), y en tal sentido, vinculamos estos postulados de los Estudios culturales con la teoría postcolonial en lo relativo a la hegemonía de saberes y prácticas. Desde la conceptualización de Quijano de colonialidad del poder ${ }^{1}$, se desprenden los de colonialidad del "ser" como del "saber" en el contexto de una mirada eurocéntrica, que si bien se comenzó a conformar en el siglo XVI -como construcción hegemónica de conceptos contrapuestos como Oriente-Occidente, primitivo-civilizado-, se mantiene en el imaginario social, la memoria histórica y las perspectivas de conocimiento (Quijano, 1997: 2000) .

Estos conceptos cruzan la problemática de este trabajo: los intereses de instituciones, investigadores y comunidades indígenas en/sobre los archivos fotográficos.

\footnotetext{
${ }^{1}$ Quijano sostiene que en América Latina y en otras regiones que fueron colonizadas, se ha impuesto un patrón de dominación a partir del sistema-mundo moderno anclado por un lado en la clasificación social de la población según criterios de raza que construyó identidades geoculturales, y por otro, a partir del sistema de control del trabajo (Quijano, 2000; 2009).
} 


\section{Fondos fotográficos estatales de indígenas: su función política}

El papel de los archivos estatales en tanto instituciones/repositorios que preservan aspectos del pasado, pero también como "organismos vivos" que cobran vida en función de sus ordenamientos y usos, ha sido analizado en relación a la construcción de la identidad nacional, aunque escasamente vinculado a las hegemonías. En nuestro país, en escasas ocasiones se ha puesto en discusión desde el ámbito científico el rol de los archivos fotográficos estatales, más allá de las esferas de la conservación y la recuperación documental, o de las discusiones sobre la documentación en general, en los que primaron los debates sobre la documentación escrita ${ }^{2}$.

La cuestión de los archivos fotográficos exige al investigador apartarse de la concepción corriente -y muchas veces utilizada por algunos cientistas sociales en la actualidad- de la imagen como analogon de la realidad, como un "documento objetivo" y por lo tanto "neutral"3; por el contrario, incita a considerarla como una construcción social y cultural, que conlleva, -entre otras-, una función política. Es por ello que también su conservación, catalogación, acceso, suponen un posicionamiento político por parte de quien se ocupa de tales acciones.

Así como la imagen fotográfica no es neutra sino una construcción de la realidad en la que intervienen elementos técnicos, ideológicos, iconográficos, estéticos, entre otros, la conformación de los archivos fotográficos tampoco deriva de configuraciones de existencia neutra e invariable, sino que tiene una "vida" que refleja los intereses de

\footnotetext{
${ }^{2}$ Existen trabajos en otros países como los de Tagg (2005) quien aborda particularmente en Francia la cuestión de la fotografía y los archivos estatales y en particular aquellos vinculados a la antropología. En la Argentina, varios estudios han tratado los archivos de la represión, donde la imagen también se impone como un tema en discusión. Véase sobre los archivos nacionales de la represión da Silva Catela y Jelin (2002). Recientemente, varios Simposios están poniendo en discusión la relación de los museos, archivos antropológicos y la investigación, tanto en nuestro país como en el exterior (un ejemplo es el Simposio "Los Archivos antropológicos de la Nación: escrituras, cuerpos, artefactos y museos", realizado en el marco del IV Congreso Interoceánico de Estudios Latinoamericanos, Mendoza, 2010). Asimismo, algunas revistas de prestigio científico han impulsado la realización de dossiers sobre estos temas, como la Revista Colombiana de Antropología vol.46(2), 2010, que aborda el tema de Etnografía y Archivos.

${ }^{3}$ Excede los intereses de este articulo referirse a los modos históricos y actuales para el abordaje de la imagen fotográfica. Una revisión de esas perspectivas desde la postmodernidad se puede encontrar en Batchen (2004). Señalamos, como algunas referencias para el acercamiento al tema, el texto ya mencionado de Tagg (2005), así como el aporte de Sekula (en Batchen, 2004), Burke (2001), Kossoy (2001), Samuel (2000), para las reflexiones desde la historia y la filosofía; Edwards (1992), Naranjo (2006 ), Belting (2007) desde la antropología; Poole (1997) desde cruces entre la sociología y la historia; Sontag (1981), Barthes (1998) y Dubois (1994) desde la sociología y la semiología; Bourdieu (2003 [1975]) desde la sociología; Becker (1974) y Harper (2002; 1988) desde esta misma disciplina con aportes desde la antropología visual; Soulages (2005) desde la estética y Flusser (2000 [1983]) desde la filosofía. Cabe señalar que estas distinciones disciplinares son difusas en la actualidad porque las discusiones teóricas y metodológicas planteadas a partir de la década de 1960 comienzan a romper los límites disciplinares en los abordajes a la imagen. En los últimos años, los Estudios Visuales proponen desde la interdisciplinariedad, un importante campo de reflexión y estudio de la imagen, entre otros, las propuestas de Mitchell (1995;2002), Mizroeff (1999), Brea (2005). Campo este último donde se ubica nuestro propio abordaje.
} 
Giordano. Instituciones, investigadores y comunidades indígenas chaqueñas.

diversos agentes que los guardan y/o que pretenden utilizarlos y difundirlos. Ello no supone solamente cuestiones de "gestión documental", como algo meramente técnico sustentado en una "desideologización" de la imagen, sino especialmente una política documental, a partir de considerar la imagen en tanto "artefacto" $y$ "medio" "que conlleva en su propia concepción, circulación y uso, una función política. Y si reflexionamos sobre archivos que contienen imágenes de indígenas, esta política debe considerarse en un contexto pretérito y actual de procesos hegemónicos y construcción de alteridades constitutivos de una colonialidad del poder a la que aludimos anteriormente.

Toda toma fotográfica donde se retrate a una persona implica violencia: en términos de Sontag “... fotografiar personas es violarlas, pues se las ve como jamás se ven a sí mismas" (2006: 54), situación que se acentúa cuando la persona representada no ha tenido ningún tipo de intervención en la demanda o requerimiento de la imagen, y más aún cuando la toma se ha producido en un contexto colonialista de sometimiento o como resultado de la arbitrariedad y colonialismo del poder, como es el caso de fotografía de indígenas ${ }^{5}$.

De tal forma, la función política de la imagen no deriva solamente del uso de la misma por agentes del poder político, sino también, por una clarificación de los modos de conservación, criterios de clasificación y usos que los archivos presentan. Pero también se abren discusiones acerca de la "propiedad" de las imágenes. Justamente referido a los archivos de la represión, Jelin se pregunta: “... de quién es el archivo? ¿Qué objetos o documentos son de propiedad colectiva y cuáles son privados? ¿Qué es la propiedad colectiva? ¿Es el Estado? Y finalmente ¿quién tiene acceso a los documentos? ¿Con qué restricciones? ¿Quién tiene el poder de decisión?” (Jelin, 2002: 2). Similares interrogantes surgen en los archivos etnográficos.

Las fotografías de indígenas, -y en el caso que nos ocupa la de indígenas chaqueños- fueron obtenidas en situaciones de sometimiento armado, de subordinación social y étnica, de explotación laboral o de interés científico ${ }^{6}$. La "arbitrariedad del poder" se manifiesta en ellas, más allá que en el contexto en que se produjeron, ese poder se encubría de un manto de "legalidad": la organización militar, académica, religiosa, burocrática, entre otras, que actuaron en los contextos de sometimiento del indígena e implicaron la obtención de miles de imágenes que, fundándose en el concepto mimético que se tenía entonces de la imagen fotográfica, fundamentaron este accionar en el "registro" y "archivo" de las mismas.

En el contexto nacional, el indígena chaqueño fue, después de las campañas militares, uno de los tantos "otros" que despertó mayor interés en el uso de la cámara

\footnotetext{
${ }^{4}$ Belting distingue a la imagen como "artefacto" (obras en imagen) y como "medio" (medios en que se comunica esa imagen, tanto en su pieza única como reproducible). Ambos aspectos aparecen indisolubles en la naturaleza de la imagen (Belting, 2007: 15-16).

${ }^{5}$ La violencia visual ejercida en situaciones como el holocausto -analizada por Didi-Huberman, 2005 - y en nuestro contexto nacional, por los regímenes militares son algunos ejemplos. Sobre esto último veáse da Silva Catela y Jelin (2002), entre otros.

${ }^{6}$ Debemos tener presente que estos contextos no son excluyentes.
} 
por diversos agentes, no solamente pertenecientes al ámbito gubernamental, sino también viajeros, fotógrafos comerciales y especialmente miembros de instituciones académicas. Las miles de imágenes con que fueron capturados los pueblos originarios de la región chaqueña desde fines del siglo XIX pasaron a integrar archivos oficiales y privados, actualmente presentes en la Argentina y el exterior.

En nuestro país, el Archivo General de la Nación posee un corpus importante de imágenes de indígenas que procedieron de revistas como Caras y Caretas, de fotógrafos comerciales o de organismos del Estado, y la Universidad estatal también ha conservado colecciones de investigadores (en especial el Museo Etnográfico "Juan B. Ambrosetti" de la UBA y el Museo de Ciencias Naturales de La Plata). Estas instituciones marcaron en nuestra experiencia diferentes posibilidades de acceso a las colecciones, siendo en el caso del archivo fotográfico del Museo de La Plata prácticamente imposible su consulta, ya que nuestro interés en consultar el mismo se inició en 2001 y se prolongó hasta febrero de $2010^{7}$. Por otro lado, muchas de las fotografías se encuentran en colecciones del exterior, entre ellos el Smithsonian (EE.UU.), Musée du Quai Branly (Paris, Francia), Museo Etnográfico de Gotemburgo (Suecia), Instituto Iberoamericano de Berlín (Alemania) ${ }^{8}$, etc., siendo también en ocasiones difícil su acceso, ya sea por derechos de autor y/o por los altos costos que demandan las instituciones para otorgar la copia digital y los derechos de reproducción de las mismas. A estos reservorios se suman las colecciones privadas, a las que en ocasiones sus propietarios posibilitan la consulta y reproducción, mientras en otras oportunidades ello se dificulta9 ${ }^{9}$. Resulta paradójico que ninguna de estas colecciones se encuentre en el Chaco, y que por lo tanto, durante más de un siglo muchas de estas imágenes hayan sido desconocidas por la sociedad chaqueña y, en particular, por los protagonistas o los descendientes de quienes fueron capturados por la cámara. El ocultamiento, el silencio, o lo que Burke denomina lo "no visto" forma parte también de las políticas respecto de la imagen y particularmente de las prácticas institucionales hegemónicas sobre esta producción cultural.

Cabe señalar, por otro lado, los diferentes criterios y categorías de organización del material fotográfico que las instituciones poseen, lo que constituye un tópico de importancia en el relato y construcción sobre/del "otro", y en los "efectos" que produce dicha sistematización ${ }^{10}$. Sekula plantea, vinculado a las representaciones visuales y la

\footnotetext{
7 Más adelante nos referiremos específicamente a esta situación.

${ }^{8}$ En el caso del Instituto Iberoamericano de Berlín, el acceso a las imágenes es mucho más flexible que en las instituciones antes mencionadas. Incluso ofrece becas para la realización de estancias de trabajo en la institución. Sobre la autorización de esta institución para la cesión de imágenes a las comunidades indígenas del Chaco volveremos más adelante.

${ }^{9}$ En tal sentido, cabe señalar la Colección Goretti con más de mil imágenes de indígenas del Chaco argentino obtenidas por la fotógrafa Grete Stern entre 1958 y 1964, cuyo propietario autorizó el uso y reproducción de las mismas y la entrega de copias a las comunidades indígenas actuales.

${ }^{10}$ Sobre el Archivo General de la Nación y la clasificación de imágenes de indígenas en el contexto de la "superabundancia" y "desborde de categorías" de imágenes véase Caggiano (2011). Los archivos antropológicos, dependiendo del momento en que fueron organizados, presentan diversos criterios
} 
Giordano. Instituciones, investigadores y comunidades indígenas chaqueñas.

fotografía, que un archivo es "una entidad paradigmática abstracta y una institución concreta" (1992: 347), aludiendo a la materialidad y a los modos en que esa materialidad puede cobrar sentido, a partir de criterios y categorías de (de)nominación, clasificación, ordenamiento.

Así, la imagen fotográfica en tanto artefacto y medio y los archivos fotográficos, en tanto entidades abstractas a la vez que concretas, son depositaria de una función política, en tanto responden a prácticas sociales y mecanismos de producción simbólica políticamente responsables, más allá de tratarse de imágenes públicas o privadas, tema que también entra en discusión en este análisis. En el caso de las imágenes del indígena chaqueño, su función política se fundamenta en diversos aspectos: las imágenes fotográficas contribuyen a perfilar identidades étnicas ${ }^{11}$, y cuando se trata de fotografías obtenidas por grupos hegemónicos a grupos subalternos, se constituyen en "identidades asignadas". Pero también la memoria que se supone está "fijada" en la representación fotográfica es (re)significada por los "trabajos de la memoria” (Jelin, 2002) en función de la propia experiencia cultural, personal y comunitaria de los diferentes receptores ${ }^{12}$, que puede ser valorado como un proceso contra hegemónico.

\section{Experiencias de investigación con archivos fotográficos}

La imagen fotográfica fue utilizada en nuestras investigaciones como "fuente", como "artefacto" y como "herramienta" de investigación.

Desde hace más de una década hemos iniciado consultas de archivos fotográficos públicos y privados que conservaran fotografías del indígena chaqueño. Esta búsqueda respondía a diversos proyectos que podrían sintetizarse en la (re)construcción de un

clasificatorios de los fondos que aluden a los usos que esta ciencia hacía de la fotografía en el momento de su organización o reordenamiento. El caso del Archivo Etnográfico Juan Bautista Ambrosetti presenta principalmente una organización según colecciones de los antropólogos que en muchos casos donaron las mismas (como la Colección Palavecino, que tiene imágenes propias de este antropólogo como también de fotógrafos comerciales y de otros antropólogos, constituyendo un fondo que remite a la fotografía como herramienta de los estudios de campo). Pero también en esta institución, como ocurre en el Museo Etnográfico Andrés Barbero cuya colección es de gran importancia para los grupos chaquenses, la clasificación se orienta por la distinción étnica de los grupos representados. Son solo algunos ejemplos que ilustran los modos de organización del material en las instituciones.

11 Numerosos trabajos que hemos realizado se encuentran en esta perspectiva que aborda los modos en que la imagen contribuye a la conformación de identidades étnicas. Véase Giordano, 2007; Alvarado y Giordano, 2007; Giordano y Reyero, 2008, entre otros.

${ }^{12}$ Las discusiones sobre el concepto de "memoria" abarcan un amplio aspecto teórico-disciplinar. Entendemos en este caso, la memoria -o más bien "las memorias"- como construcciones que no son estancas, sino como procesos que no siguen caminos lineales, que se producen en el marco de tensiones sociales que buscan legitimar un discurso social hegemónico/contrahegemónico. Los grupos indígenas chaqueños han construido sus memorias a partir de ciertos saberes, creencias, prácticas culturales, etc., en los cuales la fotografía no había cumplido ningún rol, ya que desconocían las imágenes que se les habían obtenido a sus antepasados. Por lo tanto, en estos (re)encuentros de los indígenas con las fotografías históricas, se involucran las comunidades receptoras como también nosotros en tanto investigadores sociales que nos acercamos con las imágenes como herramienta, propiciando una investigación dialógica. 
imaginario delineado históricamente sobre el indígena chaqueño. Nos encontrábamos en un territorio de identidades étnicas construidas hegemónicamente, donde los archivos pasaron a constituir en estos trabajos elementos reveladores de los modos de construir al "otro", aunque no era nuestro interés en ese momento analizarlos en su especificidad.

La eficacia simbólica de muchos de ellos, las maneras en que se conformaron y los usos que se le dieron constituían un entramado significativo de análisis que en numerosas oportunidades sustentó estos trabajos, o los limitó.

Sin embargo, fue a partir de un proyecto de (re)encuentro de las comunidades indígenas actuales con las fotografías de sus antepasados cuando se hizo más sólida la necesidad de reflexionar sobre el rol de los archivos fotográficos ${ }^{13}$. Este proyecto se originó, por un lado, en nuestro convencimiento de que las capturas históricas del indígena que planteábamos en nuestros trabajos se reproducían en la actualidad por el desconocimiento que las comunidades actuales tenían de estos fondos fotográficos. Por ello propusimos un (re)encuentro de los tres grupos étnicos que habitan la Provincia del Chaco, (toba/qom, mocovi/moqoit y mataco/wichi), con un corpus seleccionado de imágenes, (re)encuentro que nos permitió abordar las relaciones entre los modos de mirar y las prácticas culturales que emanan de la recepción de las fotografías que les fueron atribuidas históricamente como "propias".

Por lo tanto, esta posibilidad de diálogo con las comunidades indígenas utilizando la fotografía como herramienta supuso una re-utilización de las imágenes seleccionadas de los archivos que hiciéramos previamente, lo cual nos llevó a reevaluar nuestra experiencia con las instituciones de guarda de imágenes y la posibilidad de acceso y uso de las mismas que tuvimos oportunidad -o no- de tener. Cabe señalar que en esta instancia, la incorporación de otras imágenes al corpus inicial se convirtió en significativa para estos nuevos escenarios de (re)encuentro, por lo que en ocasiones realizamos consultas a nuevos archivos como también nuevas consultas -o intentos de realizarlas- a archivos en los que ya habíamos trabajado previamente.

En los primeros años de búsqueda de documentación fotográfica se dieron situaciones de lo más dispares: mientras varios archivos públicos y privados del exterior fueron accesibles a la consulta, al uso y reproducción de imágenes -ejemplos de ello constituyen el extraordinario fondo existente en el Museo Etnográfico Andrés Barbero y la colección Müller, ambos en Asunción, Paraguay-, otros fondos de radical importancia para nuestras investigaciones fueron restringidos en su acceso. Aún con las limitaciones de personal técnico con que en el momento que realizamos la consulta contaba el Museo Barbero, el archivo fotográfico, los registros e inventarios, y documentación complementaria fueron puestos a total disposición del investigador ${ }^{14}$.

\footnotetext{
${ }^{13}$ Proyecto "Captura por la cámara, devolución por la memoria. Imágenes fotográficas e identidad" (PIP 6548), iniciado en 2006, financiado por CONICET, dirigido por Mariana Giordano y en el que participaron Elizabeth Jelin, Ludmila Catela, Pablo Vila, Alejandra Reyero y Pablo Becerra.

${ }^{14}$ Advertimos que cuando iniciamos las consultas en el año 2000, ese archivo no contaba con imágenes digitalizadas ni personal que pudiera realizarlo. Pero nos permitieron llevar el equipamiento necesario y pusieron a nuestra disposición un scanner para realizar la digitalización de las mismas. De esta manera,
} 
Giordano. Instituciones, investigadores y comunidades indígenas chaqueñas.

Uno de los repositorios significativos al que tuvimos un acceso limitado fue el perteneciente al Musée de Quai Branly de Paris que conserva la colección del antropólogo Alfred Mètraux: las imágenes estuvieron en aquel momento accesibles a la consulta por lo que la limitación no respondió a la institución sino a restricciones de copyright ${ }^{15}$, razón por la cual este corpus pudo ser analizado en nuestros trabajos que se orientaron a la relación entre la antropología y la fotografía, pero no pudieron ser difundidas y por lo tanto no integraron el conjunto de imágenes utilizadas en las instancias de recepción de las comunidades indígenas actuales del Chaco.

En la Argentina, los repositorios estatales importantes son el Archivo General de la Nación, que no guarda un importante número de imágenes del indígena chaqueño, pero que son significativas del proceso de sometimiento del que fueron objeto. En este caso, las imágenes de la Expedición militar de 1884-85 (conocida como la Expedición Victorica al Chaco), se encuentran en mal estado de conservación, con pérdida considerable de la imagen. De este fondo hemos rescatado y analizado una fotografía en trabajos previos (Giordano, 2011). Como ya señalamos, otras fotos pertenecientes a la Colección Caras y Caretas e imágenes aisladas de fotógrafos que tempranamente ingresaron en el Chaco completan el corpus. De tal forma, el acceso a esta colección no ha sido uno de los problemas más importantes, pero sin embargo el descuido y deterioro (no sólo de las imágenes de indígenas chaqueños, sino del archivo fotográfico en su conjunto), es evocativo de las políticas de la imagen y de las políticas de la memoria.

Como ya señalamos, otros dos fondos documentales fueron considerados nucleares para nuestras investigaciones: el Museo de Ciencias Naturales de La Plata y el Museo Etnográfico Juan Bautista Ambrosetti (UBA, Buenos Aires) ${ }^{16}$. El acceso a las colecciones de cada uno de estos museos ha sido diferente, en el primer caso un acceso restringido que ha impedido un análisis y discusión sobre gran parte de las imágenes en nuestras primeras investigaciones, mientras que en la segunda institución hemos experimentado un amplio acceso y excelente calidad de reproducción de las imágenes, aspecto necesario en el tipo de investigaciones que llevamos adelante.

El caso del Museo de Ciencias Naturales de La Plata se convierte en un paradigma de un uso privado de archivos públicos: tanto nuestra experiencia ${ }^{17}$ como

también contribuimos con la institución, entregando los archivos digitales correspondientes para futuros usos.

${ }^{15}$ El copyright le pertenece a herederos de Métraux. Sin embargo, es el antropólogo argentino radicado en Estados Unidos Edgardo Krebs quien tiene los derechos otorgados por los herederos para la utilización y reproducción de este fondo fotográfico, habiendo organizado una exposición de impacto internacional de la que se anunciara su presentación en Buenos Aires. Por lo tanto, aún las imágenes que Métraux publicara en vida -en publicaciones científicas- no pueden ser reproducidas sin previa autorización de Krebs. Cabe señalar que hemos logrado, luego de largos trámites y pago de altos cánones, la autorización para la reproducción de algunas de estas imágenes en dos libros de nuestra autoría (Giordano, 2012), y otro que se encuentra en proceso de edición.

${ }^{16}$ Sobre un análisis de los fondos del Museo véase Podgorny, 1992.

17 Desde el año 2001 y en repetidas oportunidades intentamos consultar el Archivo fotográfico del Museo de La Plata y no pudo realizarse la consulta por habérsenos informado en un primer momento que el mismo no estaba organizado y se encontraba en proceso de sistematización de la documentación (cabe 
la de otros colegas ${ }^{18}$ ha derivado en la imposibilidad, con diferentes fundamentos institucionales, de consultar un archivo fotográfico que se fue construyendo a partir de imágenes que las diferentes secciones de esta institución fue albergando desde el siglo XIX. En nuestro caso, desde el año 2001 iniciamos las gestiones formales e informales para su consulta con resultados desfavorables, a excepción de un conjunto

señalar que en una primera oportunidad, en noviembre de 2001, nos trasladamos hasta La Plata para su consulta; a partir de entonces, y dado los $1050 \mathrm{~km}$ que separan nuestra residencia en el Chaco de esa institución, nos comunicamos previamente en forma telefónica o por mail para conocer la factibilidad de acceder al museo). En el año 2007 un investigador de ese Museo presentó una ponencia (Martínez, 2007) en el Taller "Poblaciones indígenas en la Argentina: pasado y presente" (IIGHI-CONICET), donde abordó el tema de dicho archivo, y ante nuestra pregunta sobre el acceso al mismo respondió que aún se encontraba en proceso de organización. En 2009 nuevamente solicitamos la posibilidad de su consulta y nos informaron que el mismo no estaba aún accesible; en esa oportunidad, intervino en el pedido formal la Directora del IIGHI (CONICET) donde desempeño mis funciones de Investigadora, con una nota formal a la Directora del Museo de La Plata, que en una primera instancia no fue respondida y ante la insistencia se recibió un mail de un personal del Museo aduciendo que mis consultas no constaban en los registros del Museo (cuestión cierta y lógica, ya que nunca me habían dejado consultar), y que el archivo no estaba accesible al momento. La última solicitud vía mail para acceder a la consulta fue en febrero de 2010, momento en que estaba concluyendo el proyecto "Captura por la cámara, devolución por la memoria. Imágenes fotográficas e identidad” (PIP 6548), y por lo cual realizamos un último intento de consultar el archivo y contar con imágenes para las instancias de recepción y diálogo que teníamos programadas con grupos indígenas chaqueños en Colonia Aborigen - Napalpí. Nos informaron que la imposibilidad de acceder al archivo se debía al Proyecto de conservación del mismo financiado por la British Library que llevaba adelante la institución. Es sólo un ejemplo de la imposibilidad de acceder a colecciones que corresponden a instituciones estatales que se convierten en archivos privados al que solo acceden quienes trabajan en esa institución. Ante esta situación las imágenes de este fondo documental no formaron parte de los (re)encuentros de imágenes históricas que propiciamos con las comunidades indígenas, aspecto al que volveremos más adelante.

${ }^{18}$ Citamos como ejemplo a la investigadora Inés Yujnovsky que intentó sin resultados favorables, la consulta de fondos de indígenas del sur argentinos. En su tesis de doctorado, Yujnovsky trabaja fotografías y relatos de viajes en el proceso de consolidación del estado nacional argentino. Uno de los capítulos es sobre los Apuntes Preliminares de Francisco Moreno. El análisis parte del libro publicado pero resultaba importante la comparación con los fondos originales de archivo para poder establecer la relación entre lo que se fotografío y lo que se decidió omitir en la publicación. En este caso particular Moreno omitió por completo fotos de indígenas y la investigación se enriquecería sabiendo si existieron fotos de los grupos con los que Moreno tuvo contacto. Hay publicadas algunas fotografías aisladas que realizó Koslowski (colaborador de Moreno en estos años). De modo que se puede suponer que retrataron a los caciques y sus familias pero las fotografías tomadas por los ingenieros y topógrafos del Museo de la Plata entre 1893 y 1896 no pudieron ser consultadas. Los encargados del archivo se negaron por supuestas razones de proceso de ordenamiento, conservación y catalogación que ya lleva más de cinco años. También argumentaron que esas imágenes deberían estar en cancillería porque se trata del trabajo de Moreno como perito. Pero la búsqueda apuntaba a los años anteriores al inicio del cargo en el Ministerio. Cuando finalmente se presentó una carta por escrito a la Dirección del Museo, se permitió la consulta de una porción limitada de fotografías que han sido escaneadas directamente de los negativos, que estaban sin catalogar ni referenciar (Yujnovsky, 2009). También en nuestro caso, y para otro proyecto diferente al indicado anteriormente, en una de las oportunidades en que manifestamos el interés en la consulta, se ampliaba a imágenes obtenidas por Hermann Ten Kate en sus campañas al sur argentino y los Valles Calchaquíes. Como no pudimos acceder al archivo, estas imágenes nos fueron enviadas por el Wereldmuseum de Rotterdam, donde la consulta y selección, al igual que el envío de las imágenes se realizó por mail, lo cual demuestra la apertura institucional. 
Giordano. Instituciones, investigadores y comunidades indígenas chaqueñas.

de imágenes que pertenecieron a la colección Lehmann Nitsche y que se conservaban en la Sección Antropología del Museo, las que nos fueran entregadas por investigadores de dicha división. Más allá de las diferentes respuestas que tuvimos a lo largo de los años -cuestiones organizativas del archivo, de conservación y puesta en valor del material fotográfico, etc.- que pudieran ser atendibles en cortos períodos, la situación se contradice con el acceso que tuvieron investigadores de la propia institución, que presentaron trabajos a Congresos, artículos y conferencias sobre las imágenes a las que nosotros no tuvimos contacto ${ }^{19}$. En este contexto también se produjeron problemas institucionales internos en dicho archivo y un director del mismo despedido que denunciara ocultamiento de información y desaparición de material, quien también publicó un libro con imágenes pertenecientes al fondo que nosotros intentábamos consultar $^{20}$.

Esta situación del Museo de La Plata nos lleva a reflexionar sobre tres aspectos vinculados a la problemática inicialmente planteada: por un lado, la política institucional de limitar el acceso al archivo fotográfico, que ha hecho que muchos investigadores debieran trabajar con documentación parcial obtenida de otras instituciones, como fue nuestro caso que hemos logrado la reproducción de las imágenes de la Colección Lehmann Nitsche que se encuentra en el Instituto Iberoamericano de Berlín ${ }^{21}$, mientras no pudimos acceder a aquellas que el mismo antropólogo utilizara para sus trabajos y cuyos originales podrían -no lo sabemos- encontrarse en el archivo fotográfico del Museo de La Plata ${ }^{22}$. Pero esta situación también "dispara" hacia otro aspecto que hace a la práctica académica: la imposibilidad de debatir sobre los objetos de estudio, de generar múltiples miradas y reflexiones sobre los fondos fotográficos, lo cual podría entenderse como una miopía epistemológica. Y la imposición, por consiguiente, de una "verdad" unívoca a partir de los estudios de aquellos que sí han tenido acceso a

19 Entre otros, Martínez 2007, 2009a y b; Martínez y Tamagno, 2006; Garrido, Kelly, Martínez y Podgorny, 2007. En la nota 3 del artículo de Martínez y Tamagno, expresan textualmente: "Es importante aclarar que las fotografías analizadas en este trabajo son aquellas cuyos negativos aún se conservan en el Archivo Fotográfico del Museo de La Plata, las cuales en algunos casos fueron publicadas pero en otros muchos no; además hasta el momento no se han hallado los negativos de varias de las fotografías originalmente publicadas en 1907"' (Martínez y Tamagno, 2006: 107). Esta aclaratoria de los investigadores pone de manifiesto explícitamente la consulta de material de archivo no publicado previamente, en momentos en que a nosotros se nos impedía el acceso a las colecciones.

${ }^{20}$ Nos referimos a Xavier Kriscautzky. Desconocemos las razones que produjeron su expulsión y no es nuestro interés tratar este tema, pero tuvimos conocimiento, mucho tiempo después, que durante su dirección, el archivo se abrió durante unos meses a la consulta. Además, Kriscautzky publicó en el lapso en que estuvo al frente del archivo, el libro "Desmemoria de la esperanza" (2007), utilizando los fondos del mismo. Sobre sus denuncias públicas respecto del funcionamiento del Museo, véase la nota periodística "El Museo de La Plata debe pedir perdón a las comunidades indígenas" en El Diario de La Rioja. [En línea]. Versión digital del 27/01/2010.

${ }^{21}$ Agradecemos a la investigadora Marisa Malvestitti por habernos buscado la signatura correspondiente de estas imágenes en el Instituto Iberoamericano de Berlín, y al Dr. Gregor Wolff, encargado del departamento de fotografías de dicha institución, por haber realizado el envío digital de las mismas.

${ }^{22}$ A excepción de las antes señaladas que no integran la colección del Archivo fotográfico donde se hallan los originales y que son reproducciones de imágenes de otros antropólogos que Lehmann conservaba. 
estos acervos. Otra cuestión no menos importante que surge de este acceso restringido y que demanda una aguda reflexión, alude a la imposibilidad de que las comunidades indígenas conozcan y accedan a estas imágenes, abriendo el debate acerca de su propiedad y pertenencia ${ }^{23}$.

\section{Construcciones de memoria. Las comunidades indígenas chaqueñas y "sus" imágenes}

Los aspectos antes señalados deben a la vez atenderse en relación a las comunidades indígenas chaqueñas actuales. El desconocimiento de la existencia de estas miles de imágenes por parte de ellas era completo hasta nuestra intervención a partir del acercamiento de este material. Y en este punto es donde debemos retomar las prácticas hegemónicas y la dominantes.

La colonialidad del poder ha sido asociada a la clasificación racial de la población, como “... construcción mental que expresa la experiencia básica de la dominación colonial” (Quijano, 2000: 201). Esta impronta racial donde quedaba subsumido lo cultural como elemento del folklore, se advierte en la captura colonialista de la cámara fotográfica. En este contexto, aquellos "otros" considerados en el imaginario como "reliquias" que la fotografía "sacralizaba", o como "seres inferiores" silenciados históricamente, no tuvieron, durante más de cien años, acceso a las imágenes fotográficas que de ellos se construyeron.

Podríamos preguntarnos si el hecho de que tuvieran un conocimiento de estas imágenes podría implicar -para la concepción hegemónica- una pérdida del poder institucional de quienes conservan las imágenes.

Si las representaciones visuales pueden contribuir a perfilar identidades étnicas, su desconocimiento por parte de los sujetos directamente involucrados por ser quienes aparecen retratados en las mismas, ¿no es otra estrategia para sostener imaginarios hegemónicos y construir relaciones unívocas con el mundo indígena, para mantenerlo en el rol de subalterno, sosteniendo solapadamente la misma posición racista de un siglo atrás? Si existe una memoria comunicativa en la que la imagen puede cumplir un rol relevante: el desconocimiento de esas imágenes por parte de las comunidades indígenas durante más de un siglo ¿pudo haber atentado a la construcción de ciertos aspectos de esa "memoria comunicativa" y luego, de la "memoria cultural" ${ }^{24}$. Y es posible que

\footnotetext{
${ }^{23} \mathrm{Al}$ momento de entregar este artículo consultamos sobre el acceso actual -habiendo pasado más de un año de la última consulta- del archivo del Museo de La Plata. Nos informaron que se puede consultar, aunque la reproducción de las imágenes tiene altos costos, lo que resulta difícil de afrontar para un investigador, y totalmente imposible a las comunidades indígenas. Se podrá "ver", pero no utilizar la imagen, lo que requiere el pago de un canon.

${ }^{24}$ Assmann y Gisinger, partiendo de los estudios de Halbwachs sobre la memoria colectiva, plantean dos estratos memoriales: la "memoria comunicativa" y la "memoria cultural". La primera actúa de modo directo a partir de la transmisión de los testigos de los sucesos, y es, por consiguiente, limitada a la vida de sus protagonistas. Mientras la segunda supone el esfuerzo de la comunidad de conservar y prolongar la memoria comunicativa. "Asumida por la sociedad, la memoria comunicativa deviene en cultural."
} 
Giordano. Instituciones, investigadores y comunidades indígenas chaqueñas.

esta situación pudiera haber influido en los procesos constructivos de memorias y de una historia alternativa, que no siguiera los criterios lineales y homogeneizantes de nuestras reconstrucciones. Al decir de Ricoeur, “... la memoria colectiva sólo consiste en el conjunto de huellas dejadas por los acontecimientos que han afectado al curso de la historia de los grupos implicados que tienen la capacidad de poner en escena esos recuerdos comunes con motivo de las fiestas, los ritos y las celebraciones públicas (Ricoeur, 1999:19). Enfatizando la idea de memorias como construcciones y no como algo "dado", el sentido que se le da a la historia personal y comunitaria de los propios grupos implicados podría plantearse como un escenario de disputa con las historias hegemónicas, a partir de historias/procesos contrahegemónicos.

Nuestro proyecto de acercar las imágenes a las comunidades indígenas, involucrándonos en la selección de fotos presentadas con la participación de referentes comunitarios derivó en variadas experiencias de recepción, que en todos los casos, hizo surgir un interrogante común entre los entrevistados: “¿De dónde sacaron todo ésto?” E inmediatamente una afirmación/respuesta coincidente: "Nosotros no sabíamos que ésto existía". Con ello, estaban afirmando que no tenían estos elementos para construir sus memorias e historias.

En Misión Nueva Pompeya ${ }^{25}$ (ubicada en la región del Impenetrable chaqueño), realizamos en 2007 una presentación de imágenes en el espacio que originalmente fue la Iglesia de dicha Misión indígena; las diferentes valoraciones que los receptores dieron a las imágenes en la construcción de una historia personal/comunitaria tuvo una relevancia importante en esta triangulación de relaciones entre los fondos fotográficos, nuestro interés en indagar sobre los procesos de identificación o ajenidad respecto de las imágenes y las construcciones de memorias que surgieron (Giordano, 2010). Fueron numerosas las demandas individuales que los receptores realizaron para obtener copias de las imágenes, pero también se presentaron planteos que apuntaban a la "posesión" de las imágenes como modo de articular una memoria comunitaria.

En la mayoría de los casos, los receptores no eran conscientes del origen/ ubicación/localización de las imágenes, y en ocasiones nos consultaban acerca de ello. Un joven receptor reflexionaba sobre este punto, al expresar: "Fijate cómo todos miran, cuánta gente viene... Es que nosotros no sabíamos que ésto existía... Mirá esos toldos como eran antes... A nosotros nos contaron, pero nunca los habíamos visto... Dónde

\footnotetext{
(Cheroux, 2007:221)
}

${ }^{25}$ La localidad actual es heredera de la Misión franciscana creada en 1900, que tuvo una decadencia en la década del '50 luego de la partida de los franciscanos. Se reactivó a fines de 1969 y principios del 70 con la labor de la monja Guillermina Hagen, quien constituyó una cooperativa con aserradero y obraje, pero que tras las persecuciones del gobierno militar la abandonó definitivamente. Hasta el momento que nosotros realizamos la exposición en agosto de 2007, y a pesar que este edificio ha sido declarado Patrimonio Nacional y restaurado en 1986, el mismo se encontraba cerrado, habiéndose habilitado en 2008 una biblioteca en parte de sus instalaciones. La apertura de sus puertas para esta exposición tuvo un impacto sobresaliente en toda la comunidad del poblado, quien asistió de manera numerosa y reiterada durante los días que permaneció la misma. 
estaba todo ésto?"26. También observamos acciones en las cuales numerosos receptores fotografiaban con sus teléfonos celulares las imágenes donde aparecían los toldos, como otras representaciones que aludían a costumbres y producción artesanal.

Los actos de apropiación de huellas visuales constituyeron el marco para las demandas de imágenes, que fueron sutilmente realizadas. Sin embargo, hubo casos como el de Juan Alejo donde la actitud fue diferente: cuando le preguntamos dónde pensaba que debían estar estas fotos, decía: “Todo ésto (señalando las fotos) debería estar acá, en la Misión. No sé... hacer un museo, algo, pero acá, en la Misión”"27. Sin selección, demandaba todas la imágenes ${ }^{28}$ para ser conservadas en un espacio - "La Misión"- que desde su perspectiva simbolizaba la historia de su comunidad; con ellas pretendía constituir un nuevo fondo documental "propio" 29 . Las imágenes de las que teníamos autorización fueron entregadas poco tiempo después a la recién creada biblioteca que tenía como sede el edificio de la Misión, a la vez que aquellas que fueron solicitadas en forma individual también fueron reproducidas y proporcionadas a sus demandantes.

Otro caso de gran interés en lo relativo a las apropiaciones y demandas es el que experimentamos con Juan Chico. Perteneciente a la etnia qom/toba, recopila la memoria de sus antepasados de Napalpí -en particular los hechos vinculados a la Masacre de Napalpí ${ }^{30}$-, porque sostiene la pérdida progresiva de la memoria comunicativa y la necesidad de articularla en una memoria cultural. Juan se acercó

\footnotetext{
${ }^{26}$ Entrevista a Juan Raúl Alejo. Nueva Pompeya, agosto de 2007. Se estaba refiriendo a unas imágenes obtenidas por el arqueólogo Alfredo Tomassini en 1967 en la zona de Las Vertientes que integraban el grupo de imágenes expuestas. Agradecemos al Lic. Tomassini las imágenes que nos entregara de su colección particular -que se ocupó de digitalizarlas y realizar ampliaciones-, y las referencias y observaciones que realizó de cada una de ellas. Las mismas se encuentran accesibles a la consulta en el Archivo fotográfico del NEDIM (IIGHI-UNNE/CONICET).

${ }^{27}$ Entrevista a Juan Raúl Alejo. Nueva Pompeya, agosto de 2007.

${ }^{28}$ Se habían expuesto imágenes ampliadas y otras en pequeño formato en las paredes del edificio histórico de la Iglesia de la Misión Nueva Pompeya, pero también numerosos álbumes con imágenes que cubrían casi un siglo de representaciones del indígena chaqueño (1880-1980) eran ofrecidas en pequeños álbumes a los visitantes/receptores.

${ }^{29}$ Cabe señalar que este joven encontraba en la Misión (y en su edificio como patrimonio tangible) los elementos más relevantes de su historia comunitaria, que los atribuía a la "época de los franciscanos" y a la de la "hermana Guillermina" (se refería a Guillermina Hagen, conocida popularmente como la "monja guerrillera", que actuó en la década del setenta conformando una cooperativa entre los wichi y que fuera apresada en octubre de 1973 y luego liberada). El padre de Juan Alejo había sido presidente de la mencionada cooperativa.

${ }^{30}$ En 1924 se produjo en la Reducción indígena de Napalpí una huelga de la mano de obra indígena, desencadenada por factores de índole político-económico, maltrato y explotación de que eran objeto los indígenas, en un contexto de difusión de ideas milenaristas o mesiánicas entre los pueblos indígenas chaqueños. La misma tuvo un trágico desenlace. Si bien no hay coincidencia sobre la cantidad de muertos el día 19 de julio en que se produjo la masacre -algunos refieren 200 muertos y otros cerca de 800-, la diferencia podría sustentarse en considerar las persecuciones de los 90 días posteriores o sólo aquellos que se contabiliza el día de la matanza. La comunidad hace referencia a la primera cifra. Sobre este hecho clave de la historia de los indígenas chaqueños, se han escrito numerosos estudios de corte antropológico, histórico y testimonial.
} 
Giordano. Instituciones, investigadores y comunidades indígenas chaqueñas.

a nuestra lugar de trabajo al haber tomado conocimiento de que habíamos realizado en 2006 y 2007 experiencias de recepción de fotografías con pobladores de Colonia Aborigen $^{31}$-antigua Reducción civil de Napalpí-, solicitando ver el conjunto de imágenes de indígenas chaqueños con que contábamos. Luego acotó su búsqueda a las fotos obtenidas en la zona de Napalpí, y pidió que le comentáramos de dónde eran y quiénes las habían tomado ${ }^{32}$. Al observar un conjunto de fotografías obtenidas por Lehmann Nitsche y que se conservan en el Instituto Iberoamericano de Berlín, Juan nos preguntó: “¿Estas son de Lehmann Nitsche, el del Museo de La Plata que estuvo el día de la Matanza de Napalpí?" ${ }^{33}$. Ante este interrogante sobre el origen de las imágenes y acerca de la posible existencia de otras, respondimos contando la experiencia de acceso que tuvimos a este fondo documental y la imposibilidad de consultar el archivo fotográfico del Museo de La Plata donde podrían -o no- encontrarse otras imágenes "clave" para la comunidad. La respuesta de Juan resultó contundente: "Pero si nosotros vamos a consultarlo no nos pueden decir que no. Nosotros vamos y te traemos las fotos" ${ }^{\prime \prime}$, a lo que David, otro miembro de la comunidad que participaba del encuentro agregó: "es más, si nosotros no queremos, nadie puede usar esas fotos" ${ }^{35}$.

De esta forma, Juan y David estaban poniendo en cuestión la propiedad del artefacto fotográfico, tal como en otros contextos se diera con los restos humanos que conservan los museos. Contraponían el derecho del fotógrafo sobre su obra (copyright), el derecho de la institución sobre la guarda, uso y consulta, con el derecho del fotografiado sobre su propia imagen ${ }^{36}$.

En aquel primer encuentro con Juan, nos solicitó realizar una exposición en Colonia Aborigen, lugar en el cual habíamos participado de otra experiencia de recepción en la cual Raimundo, poblador del lugar, también había propuesto realizar la misma actividad. Luego de varios inconvenientes para la ejecución de la misma, finalmente se efectuó en mayo de 2010: la selección de las imágenes la realizamos conjuntamente a Juan, y las respuestas de recepción a las mismas han sido analizadas en otro trabajo (Giordano, 2010). En esta instancia, importa señalar la fuerza de la demanda que surgió el primer día de la exposición, donde se realizaron entrevistas filmadas a algunos de los

${ }^{31}$ En dicha instancia el corpus de imágenes que se presentó era una selección de fotografías obtenidas a grupos étnicos del Gran Chaco en el lapso de un siglo aproximadamente.

32 Desde nuestra experiencia previa con los diferentes corpus documentales, le explicamos a Juan que muchas imágenes están referenciadas en archivos, publicaciones, museos, etc., como pertenecientes a una región o grupo étnico, pero que hemos observado manipulaciones en tal sentido, por lo que en muchas oportunidades no podíamos asegurar el lugar/pertenencia étnica aludida en las denominaciones históricas.

${ }^{33}$ Recordemos al respecto que en 2008 murió Melitona Enrique, considerada la última sobreviviente de la Matanza de Napalpí. En 2012 el mismo Juan Chico, como consecuencia de su interés en la memoria de su comunidad y en particular de los hechos vinculados a la Masacre, ha hallado a otro anciano sobreviviente de la misma, Pedro Valquinta, de la etnia moqoit/mocoví, quien vive en Las Tolderías.

${ }^{34}$ Entrevista a Juan Chico. Resistencia, 26 de junio de 2009.

35 Entrevista a David García. Resistencia, 26 de junio de 2009.

${ }^{36}$ Tema muy discutido a nivel internacional, ya que la normativa en los diversos países se centra en el derecho de autor. 
receptores ${ }^{37}$, entre ellos, el mismo Raimundo que años antes se había autoidentificado en una imagen obtenida por la fotógrafa alemana Grete Stern ${ }^{38}$. Mientras se filmaba la entrevista de Raimundo, comentó:
"Porque nosotros en la familia no contamos con esos recuerdos. Si tenemos, tenemos recuerdos de los 20 años, 30. Pero esas fotos que he visto y hasta ahora creo que soy yo, no tenemos en casa... Por eso decía que nos refleja la memoria: esa edad, de niños, venir a descubrirnos a los 40, 50 años... Cuando vi esa imagen, no encuentro palabras... emoción, una sorpresa. En principio una sorpresa, ¿¿Quién se llevó mi foto y dónde fue a parar?, me pregunté. Hoy tengo de vuelta ese recuerdo". ${ }^{39}$

Pero cuando la cámara se apagó, su demanda fue muy fuerte: “Esto es nuestro (señalando las imágenes). Tienen que quedar acá”40. En la conversación participaban también miembros de la Comisión Directiva de la Asociación Comunitaria de Colonia Aborigen (lugar donde se realizó la exposición), y ante la demanda de Raimundo explicamos sobre la normativa internacional respecto de las imágenes, las diferentes condiciones de acceso que algunas instituciones establecen a las mismas, ante lo cual Raimundo redobló su apuesta: "Es que esto no debería salir de acá. Se llevaron nuestra imagen, y ahora no la podemos tener"? ${ }^{41}$

Nuestro compromiso fue gestionar la entrega de aquellas fotografías de las que habíamos firmado acuerdos de uso exclusivo para nuestras investigaciones, y entregar desde ese mismo momento las que contábamos con autorización para difundir. A la vez, la exposición que estaba programada para permanecer 15 días, se extendió por nueve meses en el salón de la Asociación.

Justamente cuando fuimos a retirar las imágenes y hacer la entrega formal de las copias que permanecerían en Colonia Aborigen ${ }^{42}$, nos encontramos con Raimundo y le informamos la gestión, a lo que respondió: "Me parece bien. Pero si ellos (refiriéndose a los miembros de la Asociación Comunitaria) no cuidan las fotos, yo me voy a ir a buscar la mía" ${ }^{43}$. Los conflictos intra-grupo se manifestaban en este caso en la "guarda"

\footnotetext{
${ }^{37}$ Parte de esta experiencia integró el documental "Historias fotosensibles", dirigida por Pablo Khünert y realizada por CONICET como parte del ciclo de documentales "Vida científica", 2010.

${ }^{38}$ En 2007, en una entrevista con imágenes que le realizamos a Raimundo Barrientos se había encontrado con su propia imagen de niño en una fotografía obtenida por Grete Stern en 1964, y nos solicitó una copia de la misma que luego le fue entregada.

${ }^{39}$ Entrevista a Raimundo Barrientos. Colonia Aborigen, 5 de mayo de 2010.

${ }^{40}$ Ibid.

${ }^{41}$ Ibid.

${ }^{42}$ En ese transcurso gestionamos y obtuvimos la autorización del Instituto Iberoamericano de Berlín en enero de 2011 para la entrega de copias de las imágenes de la colección Lehmann Nitsche a la Asociación Comunitaria de Colonia Aborigen.

${ }^{43}$ Su retrato había integrado la selección de imágenes expuestas.
} 
y conservación adecuada de su propia imagen, aún cuando él ya tenía una copia en pequeño formato de la misma.

De este modo, pudimos apreciar que en varias oportunidades, los receptores entendían que las imágenes que les mostrábamos eran propiedad de los investigadores que se las acercamos, y por tanto nos demandaban por las mismas. Y por ello tampoco comprendían las razones por las que algunas de estas fotos no podían ser entregadas (nos referimos a aquellas de las que no teníamos autorización institucional para hacerlo). Fueron escasas las situaciones en que los receptores no solo comprendieron, sino que confiaron en nuestra explicación sobre la posesión institucional o privada, y las reglas de uso y circulación que de ellas se desprenden de acuerdo a la legislación actual.

De alguna manera, en las demandas que surgieron -ya sea en forma individual o comunitaria-, subyace ese concepto de dominación pretérita (en la producción y circulación de las imágenes) y captura actual (en el desconocimiento y guarda).

\section{Conclusiones: vidas, roles y "propiedad” de las imágenes}

Foucault ha sostenido que el archivo comprende “... los discursos que han dejado de ser nuestros" y su análisis sirve para establecer "que somos diferencia, que nuestra razón es la diferencia de discursos, nuestra historia la diferencia de tiempos, nosotros mismos la diferencia de máscaras" (Foucault, 1974: 131).

El hecho de contar con archivos "abiertos" despliega la posibilidad de poner en evidencia esas diferencias, discursos, historias, tiempos y máscaras que se pueden articular en prácticas y enunciados heterogéneos a partir de la socialización de las imágenes que fueron producidas desde/en procesos hegemónicos sustentados a la vez en una colonialidad del "ser" y del "saber". Las comunidades - y también los investigadores- podrían proponer lecturas descolonizadoras, que no se sostengan solamente en la linealidad ni los procesos circulares históricos, sino que, siguiendo a Mignolo (2007), se planteen como un conjunto de procesos heterogéneos.

Desde nuestro rol de investigador, entendimos que el diálogo que surgió con las comunidades a partir de las imágenes que le presentamos complementó y en muchas ocasiones creó conflictividad respecto de nuestras lecturas previas sobre este corpus ${ }^{44}$, a la vez que puso en evidencia la estrategia de la memoria cultural: Argentina, una artesana wichi de Nueva Pompeya, demandó una imagen de principios del siglo XX porque le interesaba los diseños de la vestimenta que las mujeres poseían, mientras Juan, nieto de una descendiente de la Matanza de Napalpí, pudo visualizar "marcas" de aquel episodio central en la vida de su comunidad que sólo su abuela se lo había contado, pero a las que nadie más se había referido. Señalamos sólo dos ejemplos en los cuales se puso de manifiesto la construcción de memorias desde caminos indiciales diferentes a nuestras lecturas de la imagen.

A la vez, al triangular nuestro rol, el de las comunidades, con las instituciones que conservan estas imágenes, se clarifica el verdadero rol de "organismo vivo" en

\footnotetext{
${ }^{44}$ Sobre este aspecto véase Giordano (2009) y Giordano y Reyero (2009).
} 
que se transforma un archivo a partir de estas estrategias de diálogo. Es que la imagen "vuelve a vivir" o "toma otra vida" en estas acciones de recepción. Mason plantea respecto de la vida de las imágenes y el rol que estas asumen que cuando “... entra en un contexto cultural o histórico específico, una imagen puede jugar un rol ideológico, pero cuando se mueve en él, es capaz de sacarse de encima esa acreción ideológica y de cumplir a veces roles contradictorios. Las imágenes pueden hacer historia, pero no tienen conciencia que lo están haciendo." (Mason, 2001:16) ${ }^{45}$. Esos "roles contradictorios" se vinculan con las "diferentes máscaras" a las que hacía alusión Foucault respecto del material del archivo, a la posibilidad de construir memorias e historias que puedan contradecir o dialogar con las hegemónicas.

Asimismo, ante las diversas experiencias de recepción que hemos tenido, es que entendemos que las imágenes conservadas en los archivos, -lejanas espacial y prácticamente de quienes han construido memorias de los espacios, costumbres, hechos a que las imágenes refieren-, siguen perpetuando mecanismos históricos de captura de los grupos subalternos o minoritarios, en este caso, de los indígenas chaqueños. Las imágenes guardadas, "preservadas" y "conservadas"46 podrían asumir nuevos significados y expandir los territorios de memorias si volvieran a los lugares en los cuales fueron obtenidas, al entrar en diálogo con aquellos "otros", que no tuvieron participación en la toma de la imagen más allá de su captura.

La situación antes relatada respecto del Museo de Ciencias Naturales de La Plata y el ofrecimiento de Juan de "ir nosotros a consultar las imágenes para que vos las tengas, porque a nosotros no nos pueden decir que no", se convierte en el ejemplo más claro de esa triangulación de intereses respecto de un fondo fotográfico estatal: a Juan le interesaba conocer aquellas imágenes, también quería tener la posibilidad de estudiarlas y mostrarlas a su comunidad, pero a la vez conocía nuestros esfuerzos de años para poder consultar ese archivo, y por otro lado, entendía las normativas institucionales que limitaban el acceso a las mismas. Pero en definitiva, enfatizaba que el derecho era "de ellos", es decir, de los fotografiados, y se erigía en representante de su comunidad para reclamarlas ${ }^{47}$. Se estaba poniendo en cuestión la legitimidad: ¿quiénes son los legítimos propietarios?

Así, el debate no debería circunscribirse a los "archivos abiertos", sino también a la comunidad académica y su rol para revertir las capturas históricas, para abrir el debate a la diferencia de discursos y así poder reconocer las diferentes máscaras, no sólo aquellas presentes en la representación, sino también las que refieren al rol de los archivos. Y en esa apertura, la necesidad de que las comunidades indígenas tengan

\footnotetext{
45 La traducción es nuestra.

${ }^{46}$ Conocemos las necesidades técnicas para su conservación pero en ocasiones esos criterios se constituyen en fundamentos que perpetúan un acceso restringido-, o limitadas a un uso académico -y en ocasiones de algunos "privilegiados" a su acceso.

${ }^{47}$ Nuestra negativa a obrar de este modo respondió a la ética del investigador. Ello no implicaba que Juan pudiera hacer su consulta y demanda, pero en esa instancia no se podía aceptar que lo hiciera para contribuir a nuestras investigaciones.
} 
Giordano. Instituciones, investigadores y comunidades indígenas chaqueñas.

la posibilidad de conocer esos corpus, lo que podría considerarse un ejercicio de decolonización cultural. Sólo a través del intercambio, de ampliar el ámbito de usos de la imagen, de recuperar y abrir instituciones y no personalizar los archivos restringiendo su acceso a ciertos sujetos o grupos de investigación particulares, éstos podrían dejar de estar supeditados solamente a la función administrativa o política de "registro para la historia", de desprenderse de aquella "acreción ideológica", para convertirse en "organismos vivos", creadores de diálogos, de consensos y de disensos.

\section{Referencias bibliograficas}

Alvarado, Margarita y Giordano, Mariana. 2007. "Imágenes de indígenas con pasaporte abierto: del Gran Chaco a la Tierra del Fuego". En: Revista Magallania Vol. 35 (2). Punta Arenas, Instituto del Hombre Austral, Univ. de Magallanes, pp. 15-36.

Barthes, Ronald. 1998. La cámara lúcida. Nota sobre la fotografía. Barcelona, Paidos, $5^{\circ} \mathrm{ed}$.

Batchen, Geoffrey. 2004. Arder en deseos. La concepción de la fotografía. Barcelona, Gustavo Gili.

Becker, Howard. 1974. "Photography and Sociology". Studies in the Anthropology of Visual Communication 1, pp. 3-26.

Belting, Hans. 2007. Antropología de la imagen. Buenos Aires, Katz Editores.

Brea, José Luis (ed.). 2005. Estudios visuales. La epistemología de la visualidad en la era de la globalización, Madrid, Akal.

Bourdieu, Pierre. 2003. Un arte medio. Barcelona, Gustavo Gili.

Burke, Peter. 2001. Visto y no visto. El uso de la imagen como documento histórico. Barcelona, Crítica.

Caggiano, Sergio. 2011. "El ordenamiento y la diseminación. Imágenes y categorías en el Archivo general de la Nación". En: Giordano, Mariana y Alejandra Reyero (comp.). Identidades en foco. Fotografía e investigación social. Resistencia, IIGHI-CONICET/ Facultad de Artes, Diseño y Ciencias de la Cultura -UNNE, pp. 255-284.

Cheroux, Clement. 2007. “¿Por qué sería falso afirmar que después de Auswitchtz no es posible escribir poemas?" En: Lorenzano, Sandra y Ralph Buchenhorst (ed.). Políticas de la memoria. Tensiones en la palabra y la imagen. Buenos Aires, Editorial Gorla-Univ. del Claustro de Sor Juana, pp. 219-230.

Cordeu, Edgardo y Alejandra Siffredi. 1971. De la algarroba al algodón. Movimientos milenaristas en el Chaco argentino. Buenos Aires, Juárez editor.

Da Silva Catela, Ludmila y Elizabeth Jelin (comps.). 2002. Los archivos de la represión. Documentos, memoria y verdad. Buenos Aires, Siglo XXI.

Delrio, Walter y Lenton, Diana. 2008. "Negaciones y reconocimientos del genocidio en la política indígena del Estado argentino". En: 3ras Jornadas de Historia de la Patagonia. Bariloche.

Didi Huberman, Georges. 2005. Imágenes pese a todo. Memoria visual del Holocausto. Barcelona, Paidos.

Flusser, Vilem. 2000. Towards a philosophy of photography. London, Reaketon Books Ltd.

Foucault, Michel. 1974. The archaeology of knowledge. London, Tavistock Publications.

Garrido, Martha, Tatiana Kelly, Alejandro Martínez, Irina Podgorny (2007). "Las colecciones fotográficas del Acervo Histórico de la Facultad de Ciencias Naturales y Museo de La 
Plata”. En: Entrepasados Revista de Historia, vol.16, N 31, Buenos Aires, pp.163 - 174. Giordano, Mariana. 2007. "Falsas imágenes, falsas memorias en la fotografía etnográfica". En:

IV Congreso Internacional de Teoria e Historia del Arte - XII Jornadas de CAIA. Buenos Aires, CAIA, pp. 83-96.

2010. "Las comunidades indígenas del Chaco frente a los acervos fotográficos de sus antepasados. Experiencias de (re)encuentro". En: Da Silva Catela, Ludmila, Giordano, Mariana y Jelin, Elizabeth (Eds.). Fotografía e identidad. Captura por la cámara, devolución por la memoria. Buenos Aires: Nueva Trilce, p. 21-58.

2011. "Someter por las armas, vigilar por la cámara. Estado y visualidad en el Chaco indígena". En: Sociedade e Cultura. Dossier: "Etnografias de eventos críticos na América Latina: memórias, testemunhos e traumas". Faculdade de Ciências Sociais da Universidade Federal de Goiás, v. 14, nº 2, pp. 383-400.

Artenauta.

y Alejandra Reyero. 2008. "Mostrar y mostrarse. La construcción de memorias visuales e identidades étnicas en el Chaco". En: Entrepasados. Revista de Historia, Año XVII - No 33, pp. 71-93.

. 2009. "Testigos (in)visibles. Fotografías, relatos e imaginarios sobre la "Matanza de Napalpí”. En: $10^{\circ}$ Congreso de Historia de la Fotografía. Chascomús, 4 y 5 de septiembre de 2009. Mimeo.

Harper, Douglas. 2002. "Talking about pictures: A case for photo elicitation". Visual Studies 17 (1): 13-26.

American Sociologis 19, (1): 54-70.

Kriscautzky, Xavier. 2007. Desmemoria de la esperanza. Recuperación fotográfica de Xavier Kriscautzky. Buenos Aires, Ministerio de Educación.

Jelin, Elizabeth. 2002. Los trabajos de la memoria. Madrid y Buenos Aires: Siglo XXI de España Editores y Siglo XXI de Argentina Editores.

Kossoy, Boris. 2001. Fotografía e historia. Buenos Aires, La Marca.

Martínez, Alejandro. 2007. "Sobre algunas dificultades en la utilización de la fotografía como documento histórico-antropológico. El caso del archivo fotográfico del Museo de La Plata." Taller Las poblaciones indígenas de la actual Argentina: pasado y presente. Resistencia, AEPA-IIGHI (CONICET). Inédito. .. 2009a. "Carlos Bruch. Fotógrafo documentalista". En: X Congreso de Historia de la Fotografía. Chascomús, inédito.

2009b. "Las fotografías de indígenas del Gran Chaco en el legado de Robert Lehmann-Nitsche”. Coloquio Científico IAI, inédito.

y Liliana Tamagno. 2006. "La naturalización de la violencia. Un análisis de fotografías antropométricas de principios del siglo XX”. En: Cuadernos de Antropología Social N²4. Buenos Aires, UBA, pp.93-112.

Mason, Peter. 2001. The lives of images. London, Reakting Books Ltd.

Mignolo, Walter. 2007. La idea de América Latina. La herida colonial y la opción decolonial. Barcelona, Gedisa.

Mitchell, W.J.T. 1995. "Interdisciplinarity and Visual Culture”. Art Bulletin Vol LXXVII N4, pp. 540-544.

2002. "Showing seeing: a critique of visual culture". Journal of Visual Culture. 
Giordano. Instituciones, investigadores y comunidades indígenas chaqueñas.

Vol. 1(2), pp. 165-181. (Versión en español “Mostrando el ver. Una crítica de la cultura visual". Estudios Visuales 1: 17-40).

Podgorny, Irina. 1992. "Huesos y flechas para la nación. El acervo histórico de la Facultad y Museo de la Plata”. En: Entrepasados Revista de Historia, N³, Año II, Buenos Aires, pp. 157-165.

Quijano, Anibal. 1997. "Colonialidad del poder, cultura y conocimiento en América Latina". Anuario Mariateguiano IX, pp. 113-121.

2000. "Colonialidad del poder, eurocentrismo y América Latina”. En: Lander,

E. (comp.). La colonialidad del saber: eurocentrismo y ciencias sociales. Perspectivas latinoamericanas. Buenos Aires, CLACSO, pp. 201-246. 2009. "Colonialidad del poder y Des/colonialidad del Poder". XXVII Congreso de la Asociación Latinoamericana de Sociología. Buenos Aires, pp. 1-15.

Richard, Nelly (ed.). 2010. En torno a los Estudios Culturales. Localidades, trayectorias y disputas. Santiago de Chile, CLACSO-ASDI.

Ricoeur, Paul. 1999. La lectura del tiempo perdido: Memoria y olvido. Madrid, Arrecifes.

Reyero, Alejandra. 2010. "Ver en fotos ¿̇rever en la memoria? Límites y alcances de la fotografía en la construcción de memoria e identidad de una comunidad toba". En: Da Silva Catela, Giordano y Jelin, (Eds.), cit., p.59-83.

Rosler, Marta y Carrillo, Jesús. 2007. Imágenes públicas. La función política de la imagen. Barcelona, Gustavo Gili.

Samuel, Raphael. 2000. “El ojo de la historia”. Entrepasados 18/19, pp.145-170.

Sekula, Allan. 1992. "The Body and the Archive". En Bolton, Richard (ed.). The Contest of Meaning: Critical Histories of Photography. Massachussets, The MIT Press.

Soulages, François. 2005. Estética de la fotografía. Buenos Aires, La Marca.

Sontag, Susan. 2006. Sobre la fotografía. Buenos Aires, Sudamericana.

Tagg, John. 2005. El peso de la representación. Ensayos sobre fotografías e historias, Barcelona, Gustavo Gili.

Williams, Raymond. 2000. Marxismo y literatura. Barcelona, Ediciones Península.

Yujnovsky, Inés. 2009. Viajeros a la sombra de Darwin en los confines del siglo XIX argentino. Tesis de doctorado, El Colegio de México, inédita. 